\title{
Os discursos do Fado: da subalternidade à elitização
}

\author{
Alexandre Ferreira \\ Universidade do Minho, CECS | Portugal
}

\begin{abstract}
Resumo Este artigo reflete sobre os discursos a que o Fado esteve exposto em contextos históricos específicos. Focar-nos-emos na sua variabilidade, ora associado à música subalterna, popular ou de elite, descortinando a instabilidade do significado e as estruturas que nos permitem entender a cultura num sentido mais amplo. Para tal, explorar-se-á a origem do Fado até ao seu estatuto de “canção nacional”. De seguida, discutir-se-á a classificação do Fado como património imaterial da humanidade, pela UNESCO, encarando-a como instituição produtora de discursos. $\mathrm{O}$ artigo sugere que os discursos em torno do Fado influenciam a sua valoração social e que a UNESCO, pela delimitação de critérios sobre o que deve ser considerado património da humanidade, transmite uma ideia de universalidade a algo que é subjetivo e posicional.
\end{abstract}

Palavras-chave: Fado, Discursos, Unesco, Cultura, Música.

\begin{abstract}
This article reflects on Fado discourses to which it was exposed in specific historical contexts. We will focus on its variability, sometimes associated to subaltern, popular or elite music, unveiling the instability of meaning, and the structures that allow us to understand culture in a broader sense. To do that, we will explore the origins of Fado until its status as a "national song". Then, we will discuss the classification of Fado as intangible heritage of humanity, by UNESCO, facing it as an institution that produces discourses. The article suggests that not only the discourses around Fado influence its social valuation, but also the UNESCO transmits an idea of universality to something that is subjective and positional, by delimiting criteria on what should be considered a heritage of humanity.
\end{abstract}

Keywords: Fado, Discourses, Unesco, Culture, Music. 


\section{1 produção de conhecimento pode estar ao serviço de mecanismos de poder e visóes do mundo que pretendem, muitas vezes, afirmar-se como universais. Vemos isso através da obra de Foucault (2005), quando explica como a narrativa histórica se desenvolveu em} torno do poder régio, na figura do soberano, como forma de apoiar a criação de um Direito que reiterava, pelas suas leis, a legitimidade para exercer o poder sobre os seus súbditos. Ou na obra de Lyotard (1989), pela exposição da narrativa iluminista como uma imposição de condutas nos mais variados âmbitos que, no limite, se traduzia numa tentativa de dar um sentido universal ao mundo, uma unidade que, na verdade, nunca existiu. Ou ainda, a fragmentação da identidade, tida anteriormente como algo estanque, e que se percebeu, com os contributos de Maffesoli (1998), que há, ou sempre houve, uma hibridização e mutação constante da identidade. Embora estas teorias sejam contestadas, num exercício dialético, não podemos negar a sua influência no campo da investigação científica. Caminhamos para uma descolonização do pensamento a vários níveis, num exercício de reflexão a partir da periferia para o centro, como Foucault (2005) o fez, ao analisar as relações de poder a partir dos seus últimos alvos para entender como ele se torna legítimo e aceite entre nós. Como Lyotard (1989) o fez, contestando o carácter prescritivo das metanarrativas e a sua tentativa de uniformização do mundo. Como Maffesoli (1998) o fez, centrando a análise na flexibilização da identidade em vez da sua universalidade.

Foi neste contexto que vários autores começaram também a pensar a música pela sua íntima relação com a definição e identidade dos sujeitos. Um exercício que representou uma importante viragem epistemológica, onde aspetos como o contexto cultural, político e social são tão ou mais importantes para a análise musical como os seus aspetos puramente formais (KOZA, 1994). A música é mais do que o seu texto (partitura), é mais do que uma gramática musical. Houve, de facto, um tempo em que se pensava que a beleza da música residia essencialmente na sua forma, muito por influência da notável obra de Hanslick (1854). Não obstante o facto de ser um contributo inestimável para o pensamento musical do século XIX em particular, ainda hoje nos permite discutir e pensar a estética da música, embora seja também contestada. A apreciação estética da música é, no entanto, fundamentada em determinadas visões do mundo. Por essa razão, as consideraçóes estéticas constituem-se como uma visão subjetiva, são uma forma de discurso. Tradicionalmente, a estética faz uma distinção entre o que é a "boa" e a "má" arte, e, neste sentido, assume-se como produtora de cânones de apreciação estética que têm subalternizado a cultura popular (BARKER, 2004). Na 
interpretação de Barker (2004), os conceitos de beleza, harmonia, forma ou qualidade são posicionais, ou seja, representam muito mais um discurso do que uma verdade objetiva, o que faz com que a chamada arte erudita seja apenas mais um contributo para a discussão sobre a estética e não o seu fundamento. Neste sentido, pode-se falar em estéticas (no plural) em vez de estética (no singular), uma vez que não parece ser possível, pelo menos sem uma imposição formal, falar de uma estética universal em música.

Simon Frith (2008), um autor que se dedica ao estudo da música popular, reflete sobre o papel que esta desempenha na identidade. Advoga que a música popular não pode ser pensada sem esse elemento que tantas vezes nos permite desenvolver um sentimento de posse sobre a música. Para Frith (2008), o sentimento de pertença é a chave para a estética da música, incluindo a música clássica. Se houver uma premissa universal para pensar o belo (embora seja uma tarefa um tanto falaciosa) será a de que a beleza é infinitamente posicional e, como diria Foucault (1971), a verdade é contextual e não universal.

O Fado tem-se assumido nas últimas décadas como a canção mais representativa da nação portuguesa (FONSECA, 2012; MONTEIRO, 2011; PINTO DE CARVALHO, 1903). O discurso que apela à existência de uma canção nacional tenta vincular todo um povo à ideia de que a identidade portuguesa pode ser descodificada através do Fado. Embora o texto musical do Fado, numa perspectiva mais formal (da sua estrutura harmónica e melódica), não seja de grande complexidade (e aqui evidencia-se um posicionamento teórico que privilegia o formalismo na música), é inegável a sua relevância em contexto nacional a vários níveis. O Fado é um exemplo fundamental para a discussão sobre o valor em música e sobre os seus discursos. Por valor, referimo-nos sobretudo ao valor cultural, social, e até político, mais do que o seu valor musical. De facto, consideramos que essas dimensões são importantes, ou até imprescindíveis, para a construção do seu valor musical.

Neste artigo, o conceito de discurso refere-se à produção textual ou expressões orais que concordam entre si e geram um significado (BARKER, 2004). Por outras palavras, Barker assinala que, derivado do pensamento de Foucault, o discurso é tido como o unificador da linguagem e da prática, regulando a forma como podemos e devemos falar sobre os seus sujeitos, delimitando, igualmente, quem pode falar e como pode falar. Portanto, o discurso pode assumir um papel central no que respeita à atribuição de sentido e significado. 
Como Hall (2003) preconiza, as obras culturais nascem desprovidas de qualquer valor inerente, ou seja, em todos os domínios, o valor que lhes é imputado pode ser variável, tendo em conta o seu contexto, e é sempre um constructo social. Não há, por natureza, uma verdade ou uma estética para ser decifrada dentro das obras culturais. O seu valor, o seu significado, o seu sentido, é uma produção do ser humano. Se assim não fosse, como explicaríamos que o Fado tivesse passado por tantos epítetos (discursos) ao longo do tempo? É igualmente importante ressalvar que a produção discursiva não é alheia às relações de poder que regulam todas a relações sociais, nomeadamente as relações entre classes, e que por isso podem tender para o alinhamento com forças dominantes, constituindo-se, portanto, como discursos subjetivos, que, por força do poder, se podem tornar prescritivos.

O Fado nasceu marginal, subalternizado, e hoje goza de um reconhecimento cultural incontestável (GRAY, 2011). No entanto, a sua música, embora tenha sofrido algumas alteraçôes/inovações ao longo do tempo, não foi consideravelmente descaracterizada ao ponto de podermos afirmar que os primeiros fados são totalmente distintos dos fados que se afirmam como representativos da identidade portuguesa. Se, de facto, a música tivesse um valor inerentemente atribuído não haveria razão para os discursos em torno da mesma se alterarem de contexto para contexto.

Centraremos esta reflexão no Fado, tomando-o como exemplo da variação discursiva a que os gêneros musicais podem estar sujeitos, e como isso põe em causa um suposto valor inerente e imutável das obras culturais. Por fim, gostaríamos ainda de refletir sobre a classificação do Fado a património imaterial da humanidade, por parte da $\mathrm{UNESCO}^{1}$, e o seu efeito na elitização do gênero.

\section{De marginal à “canção nacional”}

A origem do fado não é clara, havendo várias teorias em relação ao seu surgimento. Uma delas apoia a fusão de ritmos e danças trazidas pelos escravos brasileiros, nomeadamente o lundum, que acompanharam a corte de D. João VI (GALLOP, 1933; MONTEIRO, 2011). Teoria esta que Sucena (2002) não corrobora dizendo que "são coisas diferentes e inconfundíveis, e se alguma influência o primeiro [lumdum] teve no segundo [Fado] foi no caso específico do Fado dançado e batido, de que

\footnotetext{
${ }^{1}$ UNESCO - Organização das Nações Unidas para a Educação, a Ciência e a Cultura
} 
só restam hoje vagas reminiscências" (SUCENA, 2002, p. 14). Outras teorias apontam para a influência árabe no sul de Portugal ou a associação mítica ao termo Fado - que deriva do latim fatum, e que significa destino ou sina - com o ser português (GALLOP, 1933; MONTEIRO, 2011). No entanto, apesar da sua origem difusa, já em 1903, Pinto de Carvalho descrevia o Fado da seguinte forma:

\footnotetext{
Nenhuma das cançôes populares portuguesas retrata, melhor do que o fado, o temperamento aventureiro e sonhador da nossa raça essencialmente meridional e latina; nenhuma reproduz tão bem como ele - com o seu vago charme e poético - os acentos doloridos da paixão, do ciúme e do pesar saudoso. A melancolia é o fundo do fado como a sombra é o fundo do firmamento estrelado (PINTO DE CARVALHO, 1903, p. 38)
}

Neste excerto, é possível observar uma ligação entre o Fado e a personalidade aventureira e sonhadora da nação portuguesa. Aliás, o uso do termo "raça” não virá por acaso, uma vez que, segundo Foucault (2005), o "discurso das raças", inicialmente identificado pelo autor como sendo um termo que se referia à luta histórico-política entre grupos sociais, a partir do final do século XIX (mas sobretudo no século XX), adquire um sentido biológico. Não sabendo exatamente se o termo “raça” usado por Pinto de Carvalho tem essa conotação biológica, é certo que, na citação supracitada, esse termo vem associado a características de personalidade aparentemente atribuídas a todos os portugueses. Existe uma relação simbiótica entre Lisboa e o Fado, possibilitada pelo passado colonial da cidade e pela sua localização portuária, e que permitiu uma hibridização que muitos creem estar na origem do fado (GRAY, 2011). Nos poemas, podemos encontrar, não raras as vezes, a menção a vários pontos da cidade de Lisboa; miradouros, por exemplo (GRAY, 2011). Embora possamos admitir que o fado represente a cidade de Lisboa, não sabemos se ele pode ser representativo da nação portuguesa. E embora o Fado se tenha expandido geograficamente para fora de Lisboa, passando a ter grande prevalência em Coimbra, pela sua importância na formação universitária de jovens oriundos das elites sociais, a grande maioria das performances de fado continuavam a ser feitas em Lisboa (NERY, 2012).

Segundo Nery (2012), o Fado nasce das classes sociais desfavorecidas, com condições de vida difíceis, e por isso, já no final do século XIX, as suas letras continham mensagens contra a monarquia, o que fazia dele uma canção de protesto e resistência. Assim nasce o Fado: da marginalidade e das classes sociais mais "baixas”. Estava inicialmente confinado a tabernas e a casas de prostituição, e assim 
foi até ao final do século XIX (SUCENA, 2002). No entanto, já na década de 1840 se verificava a presença da nobreza nos circuitos do Fado e, 20 anos mais tarde, a presença de elementos de novos setores dominantes como quadros de magistratura, empresários, parlamentares ou administração pública (NERY, 2012). Nos finais da década de 1860, com a entrada nas indústrias do entretenimento, o Fado surge em Revistas, Teatros, espetáculos em casinos, acompanhado de uma crescente edição do repertório fadista e métodos de aprendizagem de guitarra portuguesa (NERY, 2012).

Com a fadista Amália Rodrigues, o regime do Estado Novo aproximou o Fado à identidade nacional e aos poetas “eruditos” portugueses (FONSECA, 2012). E, como Fonseca (2012) preconiza, citando Nery, esta transição duma esfera “popular” para instituições socialmente valorizadas serviu para que o Fado se tornasse legítimo. A expansão do Fado a todos os locais de entretenimento lisboetas permitiu, igualmente, que surgisse um leque de fadistas um tanto diferentes dos que reinavam até então que eram, quando mulheres, prostitutas, ou, quando homens, assumidamente marginais (NERY, 2012).

Os trânsitos sociais a que o Fado esteve sujeito, e que porventura ainda está, vão reconfigurando os discursos existentes sobre ele. Vemos, a partir da obra de Nery, que o Fado já foi marginal, da nobreza, popular ou do estado. As temáticas fadistas também se foram alterando face às conjunturas pelas quais se atravessava; tanto tinha referências à pobreza e miséria como contestaçóes à monarquia (NERY, 2012). Durante o regime do Estado Novo, a neutralidade política assumida por alguns fadistas significava o apoio à ditadura (MONTEIRO, 2011), o que atribuía ao Fado mais um epíteto - a canção do regime.

Embora as letras do Fado tenham vindo a ser alteradas ao longo do tempo, a sua música, do ponto de vista formal, não sofreu tantas mutaçôes. Nas palavras de Rodney Gallop, citado em Sucena (2002), o Fado não tem nada de exótico no que respeita à sua construção formal; as linhas melódicas e harmónicas são afetas à tradição da música da Europa central da segunda metade do século XVIII, nomeadamente países como França, Alemanha e Itália. Ainda segundo o autor, o Fado deambula entre os modos Maior e Menor, com uma estrutura simétrica, alternando sobretudo entre acordes de tónica e de sétima da dominante. É introduzido por uma pequena parte instrumental, acompanhado, geralmente, de uma guitarra portuguesa e de uma guitarra clássica (GALLOP, 1933). No que respeita ao ritmo, o acompanhamento instrumental do Fado é bastante regular. Por outro lado, os fadistas 
cantam com uma métrica mais livre, com similitudes aos cantores de jazz, aplicando inclusivamente alguns “truques” com síncopes e suspensões (GALLOP, 1933).

A partir da década de 90 começou a surgir uma nova geração de fadistas, que haviam iniciado a sua formação nas casas de Fado, e que hoje apresentam uma versão mais híbrida e menos ortodoxa. Exemplo disso é a fadista Mariza ou Mísia que vão transgredindo os pressupostos do Fado tradicional (MONTEIRO, 2011). Essas "transgressões” podem aparentar ser discretas e irrelevantes, mas introduzem novas características ao Fado:

Os signos fadistas, em princípio, estão todos lá: a formação musical voz/guitarra portuguesa/viola; o vestido negro comprido, eventualmente acrescido de xale, também preto; temas "clássicos”, como "Maria Lisboa”, “Oiça lá ó Senhor Vinho” e congêneres. Entretanto, aqui e ali começam a despontar elementos estranhos a este universo: o recurso a instrumentos de percussão de matriz africana; o brilho dos vestidos e o penteado invulgar; a dança que acompanha o canto; a ponte entre o fado e a morna, gênero musical de Cabo Verde que, como é do gosto destas disputas genealógicas, ora é saudado como matriz do fado, ora como seu descendente. (MONTEIRO, 2011, p. 154).

$\mathrm{Na}$ visão do autor, a nova geração de fadistas também rompeu com a ideia de o Fado se destinar a um público de uma faixa etária mais “velha”, sendo direcionado, hoje, também para as camadas mais jovens. Concretamente, vemos que o Fado passou dos ambientes subalternos, que lhe deram corpo, para as classes aristocráticas e estudantis, e, depois da revolução de 1974 em Portugal, deixou de ter visibilidade pela sua associação ao regime Salazarista (MONTEIRO, 2011).

O Fado goza hoje de um estatuto quase mitológico no que respeita à sua posição de destaque na "cultura portuguesa". A sua génese subalterna serve agora o discurso que o coloca como património cultural de incontestável relevância. As formações discursivas em torno do Fado não são neutras e espelham formas de lhe dar significado que, embora se possam camuflar como verdades universais, são na verdade contextuais.

Veja-se a transformação interessante do Fado, que nasce com um discurso marginal e pouco relevante, nos meandros da música "não-erudita”, para uma canção de elite, ou a mais elitizada da esfera "popular". Isto torna ainda mais evidente o caráter socialmente construído dos discursos em torno dos gêneros musicais e a ambiguidade dos termos "erudito" e "popular". A sua estrutura musical tem sido, apesar de tudo, mais constante.

É-nos sugerido que as classes sociais, por onde o Fado circula, são determinantes para a sua apreciação estética. Embora se admita que uma classe social não seja totalmente homogénea, sendo 
possível que, dentro dela, existam algumas diferenças assinaláveis, como por exemplo as de gênero, parece-nos que o juízo de valor, no sentido de ser "bom” ou “mau”, pode ser determinado pela classe social ou por causa dela, e vai muito mais além da sua estrutura e "texto" musical. Vale a pena dizer que uma classe social pode, apesar de tudo, não partilhar uma cultura comum, embora muitas vezes isso aconteça. Deve-se considerar que o juízo estético parece estar dependente das relaçóes de poder, ou seja, de quem tem legitimidade para fazer esses juízos, e também pelas limitaçóes impostas pelo discurso.

Hoje em dia, a UNESCO contribui para a consolidação do Fado como património de indiscutível relevância. Não podemos afirmar se, por causa disso, o número de ouvintes e performers aumentou, no entanto, o Fado não é certamente percepcionado como sendo mais um gênero musical “popular”, na acepção mais pejorativa do termo.

Gostaríamos, de seguida, de explorar os efeitos da ascensão do Fado a património imaterial da humanidade como possível alavanca da sua elitização e reconhecimento social.

\section{Um selo de qualidade para a "música portuguesa”}

Como estagiário da UNESCO, Nielsen (2011) teve oportunidade de conduzir um estudo etnográfico tendo como objetivo entender a noção de cultura que a mesma promove atualmente. $\mathrm{Na}$ sua interpretação, numa fase inicial, metade da década de 60 e inícios da década de 70, a UNESCO entendia a cultura num sentido mais progressista, adotando uma visão mais materialista, ou seja, a cultura podia-se traduzir essencialmente nos produtos materiais (obras de arte, por exemplo). $\mathrm{O}$ autor entende que as elites sociais desempenhariam um papel importante na transmissão de um cânone cultural para que "todos pudessem ser educados de forma a alargar o entendimento de nós mesmos [...]”2 (NIELSEN, 2011, p. 276). Rapidamente a UNESCO percebeu que este pensamento não era o mais inclusivo e por isso impulsionou um movimento que pensava a cultura num sentido mais antropológico, considerando as distinções culturais a vários níveis, tanto da sociedade como um todo, bem como os diferentes grupos sociais que a compóem (NIELSEN, 2011).

\footnotetext{
${ }^{2}$ Citação Original: "[...] everybody should become educated in order to enhance their understanding of themselves [...]"
} 
Contudo, o autor interpreta o discurso que promove a aceitação de todas as formas culturais numa perspectiva menos inclusiva, uma vez que considera que essa aceitação deve estar em linha com o código de valoração preconizado pela instituição. Refere-se a valores como a tolerância, diálogo, democracia, participação, escolha e abertura. Desta forma, nem tudo o que é legítimo culturalmente pode ou vai ser considerado para apreciação por parte da UNESCO. A instituição filtra, desta forma, a cultura que reflita o seu posicionamento teórico/ideológico.

Nielsen (2011) dá-nos conta de uma UNESCO que, através da aprovação de documentos orientadores nas suas Conferências Gerais, se torna também ela produtora de um discurso, tanto em relação à missão da instituição como sobre a noção de cultura. Os funcionários devem apresentar novas propostas e novas ideias tendo em conta esses documentos aprovados, tornando-se, afinal de contas, num mapeamento discursivo.

\footnotetext{
Mantendo isto em mente, quando os especialistas ou consultores escrevem propostas para o presente ou ação futura, as mesmas são formuladas para que encaixem com as posições dos seus superiores; por um lado isto acontece através de mecanismos hierárquicos e de censura, que os superiores aprovam, corrigindo ou dispensando propostas, e por outro lado, são os superiores que representam a posição oficial da UNESCO em encontros ou conferências $^{3}$ (NIELSEN, 2011, pp. 282-283)
}

Percebemos que mesmo numa instituição como a UNESCO, promotora da igualdade e aceitação das mais variadas expressões culturais humanas, assume a sua posição de poder, desde logo pelas restriçốes discursivas internas, mas também por uma imposição deliberada (ou não) sobre o papel da cultura na sociedade.

Em 2011, com a classificação da UNESCO, o Fado é reconhecido como algo próprio de Portugal, particularmente da cidade de Lisboa. No site da organização pode ler-se que o Fado fortalece o sentimento de pertença e identidade na comunidade Lisboeta, e que é uma canção urbana portuguesa (UNESCO, 2011). Se o Fado foi classificado, pode depreender-se que cumpriu com os requisitos da UNESCO e se enquadrava na sua noção de cultura. Se o gênero já estava de alguma forma conectada a uma suposta identidade portuguesa, a classificação fortaleceu isso mesmo. O que

\footnotetext{
${ }^{3}$ Citação Original: "Bearing this in mind, when programme specialists or consultants write proposals for present or future action, these proposals are formulated so they fit the positions of superiors; on the one hand this happens through hierarchy and censorship mechanisms, where superiors approve, correct or dismiss drafts, and on the other, it is superiors who represent UNESCO's official position in meetings and conferences."
} 
não fica claro é o porquê de o Fado ser supervalorizado em relação a todas as outras formas musicais que se podem encontrar em território português. Porquê o Fado? O que é que se lhe pode atribuir a mais do que aos cantares ao desafio tão presentes no norte de Portugal, por exemplo? É a sua história? São as suas particularidades musicais? É uma vontade política? Vejamos o conceito de património cultural imaterial preconizado na convenção da UNESCO e que pode ser consultado no site oficial da instituição:

\begin{abstract}
O termo "patrimônio cultural" mudou consideravelmente o conteúdo nas últimas décadas, em parte devido aos instrumentos desenvolvidos pela UNESCO. O património cultural não termina em monumentos e coleçôes de objetos. Também inclui tradiçốes ou expressões vivas herdadas dos nossos ancestrais e que são transmitidas aos nossos descendentes, como tradições orais, artes cénicas, práticas sociais, rituais, eventos festivos, conhecimentos e práticas relativas à natureza e ao universo ou conhecimentos e habilidades para produzir artefatos de trabalhos manuais.

Embora frágil, o património cultural imaterial é um fator importante na manutenção da diversidade cultural diante da crescente globalização. Uma compreensão do património cultural intangível de diferentes comunidades ajuda no diálogo intercultural e incentiva o respeito mútuo por outros modos de vida ${ }^{4}$ (UNESCO, 2018, p. 5)
\end{abstract}

De acordo com a definição apresentada, há uma infinidade de práticas musicais em Portugal passíveis de serem classificadas pela UNESCO. Qual é o propósito da classificação a não ser uma segregação e desequilíbrio entre as práticas culturais musicais, que pode culminar num pensamento entre aquilo que é ou não é legítimo e, por sua vez, naquilo que é ou não merecedor de uma distinção da UNESCO? Poder-se-á afirmar que a classificação serve para reconhecer práticas culturais relevantes em termos de pertença e identidade para as comunidades envolvidas, e que também auxilia à sua preservação. Assim sendo, deve-se ou não reconhecer todas as práticas culturais? O que faz de umas culturas mais autênticas do que outras? Será a questão da autenticidade relevante nos dias de hoje? Consideramos que o conceito de autenticidade não nos auxilia a entender as práticas culturais por estar sempre envolvida uma certa subjetividade na sua conceptualização. Aquilo que nos

\footnotetext{
${ }^{4}$ Citação original: The term 'cultural heritage' has changed content considerably in recent decades, partially owing to the instruments developed by UNESCO. Cultural heritage does not end at monuments and collections of objects. It also includes traditions or living expressions inherited from our ancestors and passed on to our descendants, such as oral traditions, performing arts, social practices, rituals, festive events, knowledge and practices concerning nature and the universe or the knowledge and skills to produce traditional crafts.

While fragile, intangible cultural heritage is an important factor in maintaining cultural diversity in the face of growing globalization. An understanding of the intangible cultural heritage of different communities helps with intercultural dialogue, and encourages mutual respect for other ways of life.
} 
permitirá definir o que é ou não autêntico terá por base experiências subjetivas de comunidades ou indivíduos. Além disso, falar de uma cultura autêntica é assumir de alguma forma que as culturas são estanques, porque se delimita o campo em que essa autenticidade pode ser considerada, e também porque se assume a existência de culturas inautênticas. Também o conceito de "ser fadista" tem espoletado discussões muito emocionadas e que têm por base, não raras as vezes, o conceito de autenticidade.

A UNESCO veicula, então, um conceito antropológico de cultura, no sentido daquilo que representa os modos de vida de uma comunidade. Embora relevante no estudo da cultura, essa visão tende a desconsiderar algo mais profundo. De acordo com Hall (1996), e na proposta dos Estudos Culturais, a cultura não é somente uma prática ou apenas uma simples caracterização descritiva dos modos de vida de uma sociedade; são os padróes de organização e a forma como essas estruturas se interrelacionam que são reveladoras em si mesmo. Neste sentido, é importante ter em conta tanto o contexto que leva à criação de práticas culturais como o seu efeito na teia de significados, e também como estes dois elementos se relacionam entre si. Desta forma, pode entender-se que a formação de identidades, relações de poder, formas de dar sentido e significado ao mundo que nos rodeia são mais flexíveis e conjeturais. Neste sentido, a cultura é “ordinária”, como diria Raymond Williams (2001). A vida quotidiana é a cultura no seu estado mais primitivo, mais vivo. É nesse palco que se pode perceber como se estruturam os movimentos de resistência e elitização e como se estabelecem as relações mediadas pelo poder. Poder esse, que na interpretação de Foucault (2005), é uma prática, uma ação, é algo que se exerce através de mecanismos e formas organizativas que permitem a sua existência.

Perceber como o Fado escala até ao mais alto nível de reconhecimento social é algo que nos obriga a considerar o conceito de tradiçấo seletiva utilizado por Williams (2011). O conceito referese, desde logo, à existência de uma cultura dominante que busca manter presente o que considera ser o "passado mais significativo” (WILLIAMS, 2011, p. 54). A seleção do que é importante ser ou não preservado e valorizado diz-nos mais sobre a forma como se dá a manutenção de uma hegemonia incontestada do que sobre o objeto em si mesmo. Mas como Williams (2011) nos faz saber, uma visão que admite simplesmente uma dominação através de uma ideologia bem definida e delimitada não nos auxilia na compreensão sobre a perenidade da dominação. É algo muito mais complexo e flexível, uma vez que quem domina vai negociando e acomodando visóes alternativas, e até contraditórias, da 
visão dominante, mas que, em momento algum, se permite a extrapolação que chegue ao ponto de pôr em causa toda a estrutura de poder (WILLIAMS, 2011). Esta análise que Williams apresenta é um dos centros da análise cultural contemporânea. Estas formações e estruturas fazem parte do "cultural".

Poder-se-á colocar a hipótese de que a candidatura do Fado, embora o gênero se inclua na música popular, seja fruto de uma estrutura de poder que decidiu selecionar o seu "passado mais significativo”. A escolha do Fado, e não de outro gênero, poderá representar uma vontade de quem exerce o poder. Veja-se que, pela altura da candidatura do Fado a património imaterial da humanidade, o gênero já gozava de uma notoriedade considerável e não era, de facto, subalterno ou sem voz em Portugal. A representação da nação portuguesa passa, quase inevitavelmente, pelo Fado. Se pudéssemos alocar um gênero musical a cada nação, Portugal seria o Fado. A sua sobrevalorização institucional, seja pela classe política e intelectual portuguesa, seja pela UNESCO, elitiza-o e faz transparecer um posicionamento claro quanto àquilo que se pode considerar como cultura significativa.

\section{Considerações Finais}

Neste artigo, procurou-se explorar os discursos que surgem em torno do Fado quanto à sua origem, mas também como gênero musical independente, classificado como património imaterial da humanidade pela UNESCO. De facto, em linha com o contexto histórico, social e cultural, o Fado assume-se como gênero musical subalterno, popular, de elite, e até com conotações políticas. Por um lado, sugere-nos que os significados dos gêneros musicais, além de subjetivos, são instáveis e que, por isso, a estética da música, enquanto procura pelo belo, só consegue definir critérios igualmente instáveis, contextuais e subjetivos. Por outro lado, a hierarquização dos gêneros musicais, quanto ao seu valor artístico, cultural e social, pode ser entendida como uma representação das relações de poder da sociedade em que se insere. E mesmo que em determinado momento histórico o Fado possa transparecer uma mensagem universal e consensual, como a sua ascensão a património classificado, não deixa de ser um discurso produzido social e contextualmente. Por outras palavras, o Fado, assim como outros gêneros, não possui um valor inerente e imutável porque isso depende da sua relação com classe social, gênero, etnia, entre outros. É isso que pode ajudar a explicar a distância abrupta 
entre a sua origem marginal e o status de "canção nacional". O entendimento de que os discursos são uma construção social, influenciados pelas relaçôes de poder na sociedade, é fulcral para a desconstrução de hegemonias discursivas ou culturais que mascaram, por vezes, uma verdade contextual numa verdade universal. O mesmo princípio se aplica às instituições, como a UNESCO, onde se deve observar a que discursos é que elas respondem, se criam novos, e com que objetivo. Como se expôs anteriormente, a UNESCO não é uma instituição imparcial no que diz respeito à noção de cultura, e talvez não o consiga deixar de ser. Isso será, porventura, uma outra discussão. O que se pretende relevar, neste artigo, é que a UNESCO classifica o património de acordo com o conceito e visão que lhe permite constituir-se enquanto entidade internacionalmente reconhecida para a área da cultura. Não deixa, por isso, de ser influenciada pelo contexto social, político e cultural que atravessa, passível de contestação quanto ao seu papel e ação em relação ao património e à cultura.

Hoje considera-se que o Fado deve ser preservado enquanto património cultural português, no entanto, estando ele próprio em constante reconfiguração, pode surgir uma distinção mais acentuada entre aquilo que é o Fado legitimamente classificado e as suas eventuais novas formas. As classificações a patrimônio da humanidade, do nosso ponto de vista, são reflexo de uma complexa relação de poderes e movimentos sociais, políticos e culturais que, em determinado momento histórico e social, se traduziram na classificação do Fado a património imaterial da humanidade pela UNESCO. Desta forma, há uma inequívoca legitimação do Fado por parte dum organismo internacional que, com a intenção de o preservar, também o elitiza face às demais formas culturais existentes. Portanto, as iniciativas decorridas em prol do Fado desvelam uma estrutura social, a forma como ela se organiza, os seus valores, representando isto o sentido mais amplo do conceito de cultura. A cultura é pensada, também, pela forma de dar significado ao mundo, nomeadamente pelas relaçóes entre comunidades, permeadas pelo poder, e que está presente no quotidiano de todos.

É na senda do Estudos Culturais que podemos pensar a cultura como algo vivo. Precisamente, os discursos de que temos vindo a falar são exemplos daquilo que é a cultura para os Estudos Culturais. É pelo sentido dialético entre as estruturas e organizações sociais, os padrões que elas criam e a sua influência na nossa subjetividade que podemos entender a cultura. É também assim que podemos refletir sobre as instituiçốes sociais como produtoras de sentido e significado, e, possivelmente, reprodutoras de pensamentos dominantes.

Sugere-se que a relevância social e cultural do Fado, que se intensificou com a candidatura e 
posterior aprovação a património imaterial da UNESCO, é fruto de uma estrutura que concorda em lhe atribuir essa mesma importância. No entanto, embora possa parecer uma vontade nacional, pela sua ligação à “identidade portuguesa”, que agrega a concordância de todos os portugueses, é subjetiva e posicional, cimentando a ideia de cultura digna de ser preservada, conectando-se com a missão da UNESCO e com os seus critérios. Ter a certificação institucional de que uma forma cultural deve ser preservada pode dar espaço para a criação de discursos que reproduzem a ideia de culturas legítimas e ilegítimas. Neste sentido deve-se ter em conta que este alinhamento entre instituições, esta validação concertada, é também parte do que chamamos cultura. Assim, pode ser pensada conjunturalmente e não como algo fixo e imutável. Existem, de facto, hierarquias em vários campos, seja na ciência, na política, nas artes, e importa saber como é que elas são criadas e o que dizem sobre a organização social. Por isso, consideramos importante ter em conta que os gêneros musicais não possuem qualidades inatas, nem significados ou sentidos universais, e se assim o transparecer, é porque há uma estrutura que permite a estabilização do discurso.

\section{REFERÊNCIAS}

BARKER, Chris. The SAGE Dictionary of Cultural Studies. London. Sage Publications, 2004.

FONSECA, Ricardo X. Oppositional Discourses on Fado Music: a Love-Hate Relationship. In: SANTOS, Maria do Rosário Girão; LESSA, Elisa Maria (Org.). Música, discurso, poder. Braga: Húmus, 2012, p. 173-184.

FOUCAULT, Michel. A ordem do discurso: aula inaugural no Collège de France, pronunciada em 2 de dezembro de 1970. São Paulo: Loyola, 1971.

FOUCAULT, Michel. Em Defesa da Sociedade, Curso no Collège de France (1975-1976). 4. ed. São Paulo. Martins Fontes, 2005.

FRITH, Simon. Why music matters. Critical Quarterly, v. 50, n. 1-2, p. 165-179, 2008. Disponível em: <http://dx.doi.org/10.1111/j.1467-8705.2008.00811.x>.

GALLOP, Rodney. The fado: (the portuguese song of fate). Musical Quarterly, v. 19, n. 2, p. 199213, 1933. Disponível em: <http://dx.doi.org/10.1093/mq/XIX.2.199>.

GRAY, Lila Ellen. Fado's City. Anthropology and Humanism, v. 36, n. 2, p. 141-163, 2011. Disponível em: <http://dx.doi.org/10.1111/j.1548-1409.2011.01089.x>.

HALL, Stuart. Cultural Studies: Two paradigms. In: STOREY, John (Org.). What is cultural studies? A reader. Nova Iorque: Arnold, 1996, p. 31-48.

HALL, Stuart. Notas sobre a desconstrução do "popular”. In: SOVIK, Liv; (Org). Da diáspora 
identidades e mediações culturais. Trad. RESENDE, Adelaine La Guardia; ESCOSTEGUY, Ana Carolina; ALVARES, Claudia; et al. Belo Horizonte: UFMG, 2003, p. 247-264

HANSLICK, Eduard. Do belo musical. Lisboa: Edições 70, 2015.

KOZA, Julia Eklund. Aesthetic Music Education Revisited: Discourses of Exclusion and Oppression. Philosophy of Music Education Review, v. 2, n. 2, p. 75-91, 1994.

LYOTARD, Jean-François. A Condição Pós-Moderna. Lisboa: Gradiva, 1989.

MAFFESOLI, Michel. O Tempo das Tribos: o declinio do individualismo nas sociedades de massa. Rio de Janeiro: Forense Universitária, 1998.

MONTEIRO, Tiago José Lemos. “Tudo isto (ainda?) é fado” ou a tradição já não é mais o que era: reconfigurações de um gênero musical entre a raiz e o pop. Revista Brasileira de Estudos da Canção, v. 3, p. 145-162, 2011.

NERY, Rui Vieira. Para uma História do Fado. Lisboa: Sociedade Portuguesa de Autores e Imprensa Nacional-Casa da Moeda, 2012.

NIELSEN, Bjarke. UNESCO and the "right" kind of culture: Bureaucratic production and articulation. Critique of Anthropology, v. 31, n. 4, p. 273-292, 2011.

PINTO DE CARVALHO. História do Fado. 5 ed. Lisboa: Dom Quixote, 1903.

SUCENA, Eduardo. Lisboa, o Fado e os Fadistas. 2. ed. Lisboa: Vega e Autor, 2002.

UNESCO. Basic Texts of the 2003 Convention for the Safeguarding of the Intangible Cultural Heritage. Paris: [s.n.], 2018.

UNESCO. Decision of the Intergovernmental Committee: 6.COM 13.39. v. 2017, 2011. Disponível em: <https://ich.unesco.org/en/decisions/6.COM/13.39>.

WILLIAMS, Raymond. Cultura e materialismo. São Paulo: Editora da UNESP, 2011.

WILLIAMS, Raymond. Cultura y sociedad - 1780-1950 De Coleridge a Orwell. Buenos Aires: Ediciones Nueva Vision, 2001.

\section{SOBRE O AUTOR}

Alexandre Ferreira doutorou-se em Estudos Culturais, na especialidade de Sociologia da Cultura, na Universidade do Minho e Aveiro. É investigador do Centro de Estudos de Comunicação e Sociedade (CECS) da Universidade do Minho. Atualmente leciona no Departamento de Português da Tianjin Foreign Studies University, China. ORCID: https://orcid.org/0000-0001-7811-4284. E-mail: al.barbosa.ferreira@gmail.com 